\title{
Nursing Consultation Protocol for Patients After Myocardial Revascularization: Influence on Anxiety and Depression ${ }^{1}$
}

\author{
Francisca Elisângela Teixeira Lima² \\ Thelma Leite de Araújo ${ }^{3}$ \\ Edilma Casimiro Gomes Serafim ${ }^{4}$ \\ Ires Lopes Custódio ${ }^{5}$
}

\begin{abstract}
The objective was to evaluate the influence of the Nursing Consultation Protocol in aspects of anxiety and depression in patients after myocardial revascularization using the Hospital Anxiety and Depression scale (HAD). A randomized clinical trial developed in the outpatient clinic of a public hospital in Fortaleza-Ceará. One hundred and forty six patients, who underwent myocardial revascularization, composed the population, providing the sample of 39 patients in the control group (CG) and 39 in the intervention group (IG). The results were presented in tables. Anxiety had a mean of 5.41 in the CG and a median of 5 and a mean in the IG of 5.21 and a median of 4 . Depression predominated in the CG, with a mean 4.82 and a median of 4 , while the IG had a mean of 3.79 and a median of 3 . It was found that people monitored in accordance with the Nursing Consultation Protocol had a lower percentage of anxiety and depression after six months.
\end{abstract}

Descriptors: Nursing Process; Myocardial Revascularization; Anxiety; Depression.

\footnotetext{
${ }^{1}$ Paper extracted from Doctoral Dissertation "Protocolo de consultas de enfermagem ao paciente após a revascularização do miocárdio: avaliação da eficácia" presented to Faculdade de Farmácia, Odontologia e Enfermagem, Universidade Federal do Ceará, CE, Brazil. Project CNPq \# 306149/2006-0.

${ }^{2}$ RN, Ph.D. in Nursing, Adjunct Professor, Faculdade de Farmácia, Odontologia e Enfermagem, Universidade Federal do Ceará, CE, Brazil. E-mail: felisangela@yahoo.com.br.

${ }^{3}$ RN, Ph.D. in Nursing, Assistant Professor, Faculdade de Farmácia, Odontologia e Enfermagem, Universidade Federal do Ceará, CE, Brazil. E-mail: thelmaaraujo2003@yahoo.com.br.

${ }^{4}$ RN, Hospital de Messejana Dr. Carlos Alberto Studart Gomes, CE, Brazil. Master's Student, Faculdade de Medicina, Universidade Federal do Ceará, CE, Brazil. E-mail: edilmacasimiro@yahoo.com.br.

${ }^{5}$ RN, Hospital de Messejana Dr. Carlos Alberto Studart Gomes, CE, Brazil. E-mail: iresl.custodio@gmail.com.
}

Corresponding Author:

Francisca Elisângela Teixeira Lima

Universidade Federal do Ceará

Rua Alexandre Baraúna, 1115

Rodolfo Teófilo

CEP: 60430-160 Fortaleza, CE, Brasil

E-mail: felisangela@yahoo.com.br 


\section{Protocolo de consultas de enfermagem ao paciente após a revascularização do miocárdio: influência na ansiedade e depressão}

O objetivo foi verificar a influência do protocolo de consultas de enfermagem nos aspectos relacionados à ansiedade e à depressão em pacientes após revascularização miocárdica, utilizando a escala de HAD (Hospital Ansiety and Depression). Ensaio clínico, randomizado, desenvolvido no ambulatório de um hospital público, Fortaleza, CE. Compôs a população 146 pacientes nos quais foi realizada revascularização miocárdica, constituindo a amostra 39 pacientes do grupo controle (GC) e 39 do grupo de intervenção (GI). Os resultados foram apresentados em tabelas. A ansiedade teve média no GC de 5,41 e mediana de 5 e, no GI, teve média de 5,21 e mediana de 4. A depressão predominou no GC, com média 4,82 e mediana de 4, enquanto o GI teve média de 3,79 e mediana de 3 . Constatou-se que as pessoas acompanhadas de acordo com o protocolo de consultas de enfermagem tiveram menor percentual de ansiedade e depressão, após seis meses de acompanhamento.

Descritores: Processos de Enfermagem; Revascularização Miocárdica; Ansiedade; Depressão.

\section{Protocolo de consultas de enfermería al paciente después de la revascularización del miocardio: influencia en la ansiedad y depresión}

El objetivo fue verificar la influencia del protocolo de consultas de enfermería sobre aspectos relacionados a ansiedad y depresión en pacientes después de la revascularización del miocardio, utilizando la escala de HAD (Hospital Ansiety and Depresion). Se trata de un ensayo clínico, aleatorio, desarrollado en el ambulatorio de un hospital público en Fortaleza, estado de Ceará. La población fue compuesta 146 pacientes en los cuales fue realizada la revascularización del miocardio, constituyendo la muestra 39 pacientes del grupo de control (GC) y 39 del grupo de intervención (GI). Los resultados fueron presentados en tablas. La ansiedad tuvo promedio en el GC de 5,41 y mediana de 5 y, en el GI, tuvo promedio de 5,21 y mediana de 4. La depresión predominó en el GC, con promedio 4,82 y mediana de 4; en cuanto el GI tuvo promedio de 3,79 y mediana de 3. Se constató que las personas acompañadas de acuerdo con el protocolo de consultas de enfermería tuvieron un porcentaje menor de ansiedad y depresión, después de seis meses de acompañamiento.

Descriptores: Procesos de Enfermería; Revascularización Miocárdica; Ansiedad; Depresión.

\section{Introduction}

Among the studies developed in the area of health, an interest can be observed in chronic diseases, defined as health problems with symptoms or associated disabilities that require long-term treatment.

By contributing significantly, as a causal group, to the rate of mortality in all regions of Brazil, cardiovascular diseases stand out among the chronic disorders. Furthermore, they constitute one of the principle causes of prolonged hospital stay and are responsible for the allocation of public resources in hospitalizations in Brazil. The economic burden of cardiovascular diseases has grown exponentially in recent decades ${ }^{(1)}$.

Based on these considerations, the necessity to develop strategies to increase the practice of self-care was perceived in order to control risk factors, minimize cardiovascular complications after surgery and to promote improved quality of life of patients. Among the work strategies, the nursing consultation was chosen, due to 
it being an effective strategy for early detection of health disorders and for monitoring the imposed measures, which address the welfare of the people involved. It is an action that is distinguished among the various ways to care because it enables the person to person approach, establishing the interpersonal relationship of concrete help in the face of cultural variables(2).

After myocardial revascularization surgery, the patient must go through the rehabilitation process, which is dynamic, health-oriented and able to help them achieve the highest possible level of physical, mental, spiritual and emotional health. The rehabilitation process helps the person achieve an acceptable quality of life with dignity, self-esteem and independence ${ }^{(3)}$.

Among the most common emotional disorders following heart surgery, anxiety and depression are prominent. For their assessment, it is important that health professionals use a validated scale such as the Hospital Anxiety and Depression Scale (HAD) which evaluates the changes as separate constructs. This is a simple tool, but with the power to reveal cases of mood disorders that could go unnoticed by the treatment team ${ }^{(4)}$.

Given these considerations, the goal of this study was to verify the influence of the nursing consultation protocol in aspects related to anxiety and depression, six months after myocardial revascularization surgery, using the HAD scale and comparing to a control group.

\section{Materials and Methods}

The study was a randomized clinical trial, developed in the outpatient clinic of a public hospital, a reference in Cardiology, located in the city of Fortaleza, CE. In this study, for a period of six months, a nursing consultation protocol was applied to people who had undergone myocardial revascularization surgery (MR), for further observation of its effects in relation to another group of patients, who also underwent MR without being accompanied by the protocol.

Adult and elderly patients of both sexes who met the following inclusion criteria participated in the study: to be the first myocardial revascularization surgery, regardless of the type and number of grafts (saphenous vein or mammary), to perform the surgery in the period of data collection in the above-mentioned hospital and to consent to participate in the proposed follow-up by the nurse during the rehabilitation period.

And as exclusion criteria: to undergo other surgery concomitant to the $M R$, to have gone through another surgical procedure in the first month after surgery and to live outside the metropolitan area of Fortaleza, since the movement of patients resident in other cities or other states is very expensive.

It was also necessary to define the criteria for discontinuation in the study, which were: to die during the monitoring period, to change residence from the metropolitan area of Fortaleza to another city, to decide not to continue participating in the study, to acquire a disability that prevented attendance of the consultations at the outpatient clinic, or to not attend two consecutive visits.

During the period of data collection, 146 patients underwent myocardial revascularization surgery. However, 82 patients met the inclusion criteria, of whom 42 belonged to the control group and 40 to the intervention group. In each group one patient was discontinued due to death and in the control group, two patients did not return for the outpatient postoperative review. Thus, each group consisted of 39 patients. The randomization of the groups was as shown below.

1. Control Group (CG): composed of patients who met the inclusion criteria and had myocardial revascularization surgery on odd days $(1,3,5,7 \ldots 31)$ of the months from September 2005 to March 2006. These patients, totaling 39, were monitored postoperatively after hospital discharge, according to the conventional method of treatment, i.e. the outpatient clinic cardiologist only. The patients in this group were assessed by the researcher at two points (on the day before or the day of hospital discharge and at six months after, coinciding with the medical consultation).

2. Intervention group (IG): also composed of 39 patients, who, like the CG, met the inclusion criteria and underwent myocardial revascularization surgery on even days $(2,4,6 \ldots 30)$ throughout the same period. These patients were submitted to the nursing intervention, whereby, in addition to the researcher's evaluation, on the day before or the day of hospital discharge, they also received guidance on self-care activities for the recovery of health and the prevention of complications, emphasizing the need to maintain a healthy lifestyle. The subsequent consultations were implemented by the researcher at one, two, four and six months. After hospital discharge, patients in the IG were monitored by doctors of the institution in the same way as those of the CG.

In the nursing consultation protocol for patients after myocardial revascularization surgery, there are targets and interventions that should be met, conforming to the 
real needs of the patient. The main goals were: to gain the confidence and trust of the patient, to raise nursing problems, to evaluate the physical and psychological conditions of the patient, to explain about the surgery and related questions, to raise awareness about the ongoing therapy and to solve or minimize changes in health.

On the day of the last visit, in addition to the evaluation carried out by the researcher, all patients were referred to a nurse of the institution for further evaluation using the Hospital Anxiety and Depression (HAD) scale. The evaluation of the clinical nurse was carried out with all patients (IG and CG), without her knowing to which group the patient belonged, thus avoiding biased results.

As mentioned, the HAD scale was used, which contains two subscales: One for anxiety and the other for depression. This scale has seven multiple-choice questions for each subscale, each question containing four items with values 0 (zero), 1 (one), 2 (two) and 3 (three), zero being the best score and the three worst. The total score ranges from 0 (zero) to 21 (twenty one) per subscale(4).

The use of this instrument was chosen for the following reasons: it is intended to detect mild degrees of affective disorders in a non-psychiatric environment, it is short and can be completed quickly, it evaluates anxiety and depression separately, and when validated in Brazil, it was found that in clinical practice, the use of HAD could assist in the detection of cases of mood disorders that require treatment ${ }^{(4)}$.

The results were analyzed descriptively and presented using tables. The data were compiled and analyzed using the computer programs: Excel 2003, Word 2003, SPSS 13.0 and R 2.4.1.

In order to meet the Resolution $n^{\circ} 196 / 96$ of the National Health Commission, the project was approved by the Research Ethics Committee of the hospital under $n^{\circ} 292 / 05$. All participants were informed about the objectives of the study and signed a free prior informed consent form agreeing to participate in the study. Anonymity in the dissemination of information and freedom to participate or not in the study was guaranteed.

\section{Results}

\section{Characterization indicators}

By comparing the two study groups in relation to their sociodemographic characteristics, similarity was found for gender, males predominated (62.8\%), with a mean age of approximately 65 years, ranging from 38 to 86 years, low education, in which $73.1 \%$ had not completed elementary education, prevalence of patients with a household income below one minimum wage (55.1\%) whose income came from pensions, $65.4 \%$ had family history of ischemic cardiopathy and $82.1 \%$ were Catholic. Among the characterization indicators, significant difference was found $(p=0.033)$ only in marital status, since the CG had a higher percentage $(87.2 \%)$ of people married or in stable relationships, against $64.1 \%$ of the IG.

\section{Indicators of aspects relative to anxiety and depression, according to the HAD scale}

Because the HAD scale addresses anxiety and depression as different issues alternately, both were analyzed separately. Initially, the average number of patients who felt anxiety after six months of surgery was determined.

Anxiety was assessed at the end of the study and had a mean in the CG of 5.41 and a median of 5, while the IG had a mean of 5.21 and a median of 4 .

Table 1 - Distribution of participants in the intervention and control groups, according to the questions of the HAD scale that assess anxiety. Fortaleza, CE, 2006

\begin{tabular}{|c|c|c|c|c|c|c|c|}
\hline & \multicolumn{2}{|c|}{ Control } & \multicolumn{2}{|c|}{ Intervention } & \multicolumn{2}{|c|}{ Total } & \multirow{2}{*}{ Fisher exact tes } \\
\hline & $\mathrm{n}^{\circ}$ cases & $\%$ & $\mathrm{n}^{\circ}$ cases & $\%$ & $\mathrm{n}^{\circ}$ cases & $\%$ & \\
\hline \multicolumn{8}{|l|}{ Tense and nervous } \\
\hline Never, or some parts of the day & 28 & 71.8 & 30 & 76.9 & 58 & 74.4 & \\
\hline Almost all of the day & 11 & 28.2 & 9 & 23.1 & 20 & 25.6 & \\
\hline Total & 39 & 100 & 39 & 100 & 78 & 100 & $p=0.796$ \\
\hline \multicolumn{8}{|l|}{ Fear of something bad happening } \\
\hline Do not feel or do not worry about it & 28 & 71.8 & 33 & 84.6 & 61 & 78.2 & \\
\hline Yes and/or very intense & 11 & 28.2 & 6 & 15.4 & 17 & 21.8 & \\
\hline Total & 39 & 100 & 39 & 100 & 78 & 100 & $p=0.272$ \\
\hline \multicolumn{8}{|l|}{ Worry } \\
\hline Never, or some parts of the day & 25 & 64.1 & 26 & 66.7 & 51 & 65.4 & \\
\hline Almost all of the day & 14 & 35.9 & 13 & 33.3 & 27 & 34.6 & \\
\hline Total & 39 & 100 & 39 & 100 & 78 & 100 & $p=1.000$ \\
\hline
\end{tabular}


Table 1 - Continuation

\begin{tabular}{|c|c|c|c|c|c|c|c|}
\hline & \multicolumn{2}{|c|}{ Control } & \multicolumn{2}{|c|}{ Intervention } & \multicolumn{2}{|c|}{ Total } & \multirow{2}{*}{ Fisher exact test } \\
\hline & $\mathrm{n}^{\circ}$ cases & $\%$ & $\mathrm{n}^{\circ}$ cases & $\%$ & $\mathrm{n}^{\circ}$ cases & $\%$ & \\
\hline \multicolumn{8}{|l|}{ Peaceful and relaxed } \\
\hline Always or most of the time & 32 & 82.1 & 31 & 79.5 & 63 & 80.8 & \\
\hline Rarely or never & 7 & 17.9 & 8 & 20.5 & 15 & 19.2 & \\
\hline Total & 39 & 100 & 39 & 100 & 78 & 100 & $p=1.000$ \\
\hline \multicolumn{8}{|l|}{ Unpleasant feeling of nervousness } \\
\hline Never or only some times & 37 & 94.9 & 37 & 94.9 & 74 & 94.9 & \\
\hline Almost all the time & 2 & 5.1 & 2 & 5.1 & 4 & 5.1 & \\
\hline Total & 39 & 100 & 39 & 100 & 78 & 100 & $p=1.000$ \\
\hline \multicolumn{8}{|l|}{ Agitation } \\
\hline Absolutely never & 33 & 84.6 & 35 & 89.7 & 68 & 87.2 & \\
\hline A lot & 6 & 15.4 & 4 & 10.3 & 10 & 12.8 & \\
\hline Total & 39 & 100 & 39 & 100 & 78 & 100 & $p=0.737$ \\
\hline \multicolumn{8}{|l|}{ Sensation of anxiety or fear } \\
\hline Never or rarely & 31 & 79.5 & 32 & 82.1 & 63 & 80.8 & \\
\hline Frequently or most of the time & 8 & 20.5 & 7 & 17.9 & 15 & 19.2 & \\
\hline Total & 39 & 100 & 39 & 100 & 78 & 100 & $p=1.000$ \\
\hline
\end{tabular}

In relation to the presence of anxiety, evaluated using the HAD scale, no significant difference ( $p>0.05)$ between the CG and IG was found, after six months of monitoring.

Considering the data in Table 1 , although no significant difference was found between the groups, there was a predominance in all indicators of anxiety for people in the CG.

In relation to the presence of depression after six months of surgery, the mean of patients that presented depression was also established and, subsequently, each indicator was examined individually.
According to the analysis, indicators of depression were more present in the CG, with a mean of 4.82 and standard deviation of 4.62 , while the IG had a mean of 3.79 and standard deviation of 3.06. It was found that the people monitored according to the nursing consultation protocol had a lower percentage of depression after six months of monitoring. However, there was no significant difference $(p>0.05)$ between groups. Nevertheless, according to the findings, the group monitored with a greater frequency (IG) showed lower rates of depression.

Table 2 - Distribution of participants in the intervention and control groups, by the evaluation of depression, according to the HAD scale Fortaleza, CE, 2006

\begin{tabular}{|c|c|c|c|c|c|c|c|}
\hline & \multicolumn{2}{|c|}{ Control } & \multicolumn{2}{|c|}{ Intervention } & \multicolumn{2}{|c|}{ Total } & \multirow{2}{*}{ Fisher exact test } \\
\hline & no cases & $\%$ & no cases & $\%$ & no cases & $\%$ & \\
\hline \multicolumn{8}{|l|}{ Enjoy the same things } \\
\hline Certainly in the same way & 30 & 76.9 & 30 & 76.9 & 60 & 76.9 & \\
\hline Only a little or do not enjoy anything & 9 & 23.1 & 9 & 23.1 & 18 & 23.1 & \\
\hline Total & 39 & 100 & 39 & 100 & 78 & 100 & $p=1.000$ \\
\hline \multicolumn{8}{|l|}{ Able to laugh and find things funny } \\
\hline Same as always & 28 & 71.8 & 30 & 76.9 & 58 & 74.4 & \\
\hline Currently much less or not at all & 11 & 28.2 & 9 & 23.1 & 20 & 25.6 & \\
\hline Total & 39 & 100 & 39 & 100 & 78 & 100 & $p=0.796$ \\
\hline \multicolumn{8}{|l|}{ Feel happy } \\
\hline A large part of the day & 29 & 74.4 & 34 & 87.2 & 63 & 80.8 & \\
\hline Few times or never & 10 & 25.6 & 5 & 12.8 & 15 & 19.2 & \\
\hline Total & 39 & 100 & 39 & 100 & 78 & 100 & $p=0.250$ \\
\hline \multicolumn{8}{|l|}{ Feel slow and clumsy } \\
\hline Never or some times & 35 & 89.7 & 35 & 89.7 & 70 & 89.7 & \\
\hline A lot or a large part of the day & 4 & 10.3 & 4 & 10.3 & 8 & 10.3 & \\
\hline Total & 39 & 100 & 39 & 100 & 78 & 100 & $p=0.250$ \\
\hline
\end{tabular}


Table 2 - Continuation

\begin{tabular}{|c|c|c|c|c|c|c|c|}
\hline & \multicolumn{2}{|c|}{ Control } & \multicolumn{2}{|c|}{ Intervention } & \multicolumn{2}{|c|}{ Total } & \multirow{2}{*}{ Fisher exact test } \\
\hline & no cases & $\%$ & no cases & $\%$ & no cases & $\%$ & \\
\hline \multicolumn{8}{|l|}{ Lost interest in personal appearance } \\
\hline Look after myself as always & 26 & 66.7 & 34 & 87.2 & 60 & 76.9 & \\
\hline Do not look after myself as I should & 13 & 33.3 & 5 & 12.8 & 18 & 23.1 & \\
\hline Total & 39 & 100 & 39 & 100 & 78 & 100 & $p=0.058$ \\
\hline \multicolumn{8}{|l|}{ I look forward with enjoyment to things } \\
\hline As always & 28 & 71.8 & 37 & 94.9 & 65 & 83.3 & \\
\hline Less than before & 11 & 28.2 & 2 & 5.1 & 13 & 16.7 & \\
\hline Total & 39 & 100 & 39 & 100 & 78 & 100 & $p=0.013$ \\
\hline \multicolumn{8}{|c|}{ Able to enjoy reading books or watching television } \\
\hline Often & 31 & 79.5 & 30 & 76.9 & 61 & 78.2 & \\
\hline Few times or never & 8 & 20.5 & 9 & 23.1 & 17 & 21.8 & \\
\hline Total & 39 & 100 & 39 & 100 & 78 & 100 & $p=1.000$ \\
\hline
\end{tabular}

Only one of the questions showed significant difference $(p<0.05)$ - look forward with enjoyment to things - represented by $94.9 \%$ in the IG and $71.8 \%$ in the CG. The other indicators showed no significant difference ( $p>0.05)$. By comparing the CG with the IG, there was a higher percentage of people of the IG with the ability to laugh $(76.9 \%)$ with happiness $(87.2 \%)$ and with interest in their personal appearance $(87.2 \%)$; in the CG these percentages were $71.8,74.4$ and $66.7 \%$ respectively. A higher prevalence of indicators of depression in the patients in the control group was detected.

\section{Discussion}

The evaluation of anxiety and depression was carried out at just one moment, that is, six months after hospital discharge, with the application of the HAD scale by a clinical nurse. As previously discussed, the results of the indicators of anxiety showed no significant difference between the two groups, however, in the analysis of depression, one indicator showed a significant difference, looking forward with enjoyment to things, and there was a higher percentage of people of the CG having a decreased interest in personal appearance.

No studies were found on the implementation of the HAD scale in revascularized patients, after six months of discharge. However, in a transversal study of psychiatric evaluation a $39 \%$ prevalence of mood disorders (20.5\% of "cases" of anxiety and 33\% of "cases" of depression) was found among 78 patients from a medical clinical ward after $48-72 \mathrm{~h}$ of hospitalization

In a study conducted in São Paulo, $17 \%$ of heart operation patients had some psychological disorder that persisted with varying intensity until one year after surgery, where changes were: memory deficit, difficulties in problem solving, attention and concentration deficit, delirium, crying spells, insomnia, depression, behavioral disorders and intellectual changes ${ }^{(5)}$.

Another study noted that hospital discharge often cause much anxiety, since it involves doubts, for both the patient and the family. The individual is in the process in which they are leaving a place where they were offered assistance by trained professionals, to return home, the place where a family member will have to develop the role of caregiver(6).

Giventhisreality, nursesand otherhealth professionals who care for individuals after myocardial revascularization should be alert to the features of mood change, among them anxiety and depression. The evaluation of these factors could contribute to the detection of individuals with more rehabilitation difficulties, because anxiety and depression may reflect feelings of inability to change and maintain behaviors conducive to cardiovascular health, such as: adoption of a healthy diet, practicing physical exercise and cessation of smoking.

The Ministry of Health has adopted various initiatives to reduce the impact of non-transmissible diseases in the Brazilian population, especially cardiovascular diseases. However, it emphasizes the need to develop permanent and continuing strategies for the entire population, because what is being carried out is not sufficient for the elimination of the fraction of potentially preventable disease. If preventive measures were adopted more vigorously, the epidemiology of cardiovascular diseases could be drastically modified in the next fifty years ${ }^{(7)}$.

The nurse must, however, also establish strategies to help the patient and the family to set realistic and attainable goals for the individual and the family at each different moment, stimulating them in the continuation of the effort to seek and achieve new goals that are being established, each at their own time(6). 
The inclusion of the family in the care is based on a study conducted in the city of Goiânia, GO, with people who had experienced myocardial revascularization surgery, in which it was observed that the family was an important source of emotional and social support, and contributed to the confrontation of both, problems related to the health process and illness, as well as other social problems that involve the quotidian life of these people(8).

Moreover, it is necessary that health professionals support the patient and family, which requires the involvement and commitment of the professionals with the subjects and their needs.

It is therefore necessary to promote the support and to construct bonds with the assisted individuals, because, as is understood, it is not possible to accommodate the health needs of people, listening to and understanding them, without making compromises(9).

A warning is important here: periodic attendance of medical consultations for patients with cardiovascular diseases, especially those who have already experienced a surgical intervention, such as myocardial revascularization, is vital for the evaluation of health status, especially of heart function, and for them to receive their prescriptions. Likewise, monitoring is essential in nursing consultations, focusing on the orientation and supervision of drug and non-drug treatment, such as control of the changes in lifestyle by encouraging the practice of self care.

All this can be facilitated with the implementation of the nursing consultation protocol. Regarding the cost of this, although the actual amount spent on its realization has not been calculated, the average cost was low compared with the benefits gained. In one study, in which the cost was measured by time spent by the nurse on orientation on reducing risk factors, it was found that the time used to orient patients who underwent nursing interventions varied from 80 to 240 minutes, with an average total of 204.3 minutes/patient over six months ${ }^{(10)}$. In accordance with the norm, the cost of one hour of nursing time is $R \$ 15.00$, i.e. the total cost per patient during this period is $\mathrm{R} \$ 51.08$. Therefore, this cost is negligible and can not constitute an impediment to the nurses' performance in the implementation of the nursing consultation protocol.

Finally, in recent years, strong emphasis has been placed on the identification of treatments that may produce an impact on morbidity and mortality in ischemic cardiopathy. However, the scientific evidence has not been translated into clinical practice in many institutions ${ }^{(11)}$.

\section{Conclusions}

As evidenced using the HAD scale, the nursing consultation protocol influenced the control and/or reduction of aspects related to anxiety and depression. As verified, the IG had a lower percentage of people with anxiety and/or depression, after six months of monitoring, than the CG, and, although there was no significant difference between the groups, the control group had a higher prevalence of indicators of anxiety and depression in its patients.

From these results, the importance of the nursing consultation to the patient that underwent myocardial revascularization was noted. It is believed that satisfactory results were only possible because of the use of the nursing consultation protocol, which made possible a systematic evaluation of the patient, raising their real problems for the planning and implementation of nursing interventions, establishing priorities in the adoption of measures, principally those that involve changes in behavior, habits and lifestyle, understanding the patient in a holistic manner, in the physical, social, spiritual and emotional dimensions.

Moreover, aiming at greater efficacy, it is recommended that evaluations be repeated periodically and successively, allowing a precise comparison of the patient's progress, determining if there was progress or regression.

This individualized approach, through nursing consultation, for the care of the patient, requires of the nurses the employment of their time, knowledge, expertise and planning to improve the quality of care and obtain satisfactory results in the maintenance or restoration of the health of the patient.

Despite the satisfaction obtained from the results, it is considered appropriate to conduct further studies with a larger sample and with more control over the variables, thus, providing a more consistent experimental basis to the current study, promoting the standardization of nursing care to this group of clients in the control of anxiety and depression. 


\section{Referências}

1. Castro LCV, Franceschini $S$ do CC, Priore SE, Pelúzio M do CG. Nutrition and cardiovascular diseases: the risk markers in adults. Rev Nutr 2004; 17(3):369-77.

2. Zagonel IPS. Consulta de Enfermagem: um modelo de metodologia para o cuidado. In: Westphalen MEA, Carraro TE, organizadoras. Metodologias para a assistência de enfermagem: teorizações, modelos e subsídios para a prática. Goiânia: AB; 2001. p.41-56.

3. Lipp MN, Novaes LE. O stress. $4^{a}$ ed. São Paulo (SP): Contexto; 2000.

4. Botega NJ, Bio MR, Zomignani MA, Garcia C Junior, Pereira $W A B$. Transtornos de humor em enfermaria de clínica médica e validação de escala de medida (HAD) de ansiedade e depressão. Rev Saude Publica 1995; 29:355-63.

5. Oliveira MFP, Ismael SMC. Rumos da Psicologia Hospitalar em Cardiologia. Campinas (SP): Papirus; 1995.

6. Carvalho ARS, Matsuda LM, Stuchi RAG, Coimbra JAH. Investigando as orientações oferecidas ao paciente em pós- operatório de revascularização miocárdica. Rev Eletrônica Enfermagem [Internet]. 2008;10(2):504-12. Disponível em: http://www.fen.ufg.br/revista/v10/n2/v10n2a21.htm

7. Polanczyk CA. Fatores de risco cardiovascular no Brasil: os próximos 50 anos! Arq Bras Cardiol. 2005;84(3):199-201.

8. Vila VSC, Rossi LA. A qualidade de vida na perspectiva de clientes revascularizados em reabilitação: estudo etnográfico. Rev. Latino-Am. Enfermagem. 2008; 16(1):7-14.

9. Leonello VM, Oliveira MAC. Competências para ação educativa da enfermeira. Rev. Latino-Am. Enfermagem. 2008; 16(2):177-83.

10. Goldmeier S, Castro I. A teoria do autocuidado no manejo dos fatores de risco (obesidade, hipertensão e tabagismo) em pacientes pós-infarto agudo do miocárdio. Rev AMRIGS. 2005; 49(3): 149-54.

11. Stein R, Alboim C, Campos C, Mello RB de, Rosito GA, Polanczyk CA. Variabilidade entre cardiologistas na abordagem aos pacientes em prevenção secundária da cardiopatia isquêmica. Arq Bras Cardiol. 2004; 83(3):219-22. 